XVII Simpósio Brasileiro

de Geografia Física Aplicada

I Congresso Nacional

de Geografia Física
OS DESAFIOS DA GEOGRAFIA FÍSICA NA FRONTEIRA DO CONHECIMENTO

Instituto de Geociências - Unicamp

Campinas - SP

28 de Junho à 02 de Julho de 2017

\title{
MAPEAMENTO AMBIENTAL PARTICIPATIVO (MAP) EM ILHA COMPRIDA (SP) COMO SUBSÍDIO À GESTÃO E PLANEJAMENTO DE ÁREAS COSTEIRAS
}

\author{
${\text { Viviane Gomes de } \text { Araújo }^{(a)} \text {, Jeovanes Lisboa da Silva Filho }}^{(\text {b) }}$, Salvador Carpi Junior ${ }^{(c)}$
}

\author{
(a) Instituto de Geociências, Universidade Estadual de Campinas, vivianegomes@ige.unicamp.br \\ (b) Departamento de Geografia, Universidade de Pernambuco, Campus Garanhuns, jeovanelisboa@ hotmail.com \\ (c) Instituto de Geociências, Universidade Estadual de Campinas, salvador@ige.unicamp.br
}

\section{Eixo 4: DINÂMICA E GESTÃO DE ZONAS COSTEIRAS}

\begin{abstract}
Resumo
Os ambientes costeiros são reconhecidamente áreas frágeis devido a fatores geográficos e geológicos. O aumento da ocupação humana nos litorais potencializa a degradação ambiental. Neste trabalho, apresenta-se o Mapeamento Ambiental Participativo como instrumento para auxiliar a gestão e planejamento de áreas costeiras e discute-se a experiência inicial de sua aplicação na Ponta da Praia Norte, no município de Ilha Comprida (SP), área de uso e ocupação desordenada de suas terras, e suscetível a processo de erosão costeira.
\end{abstract}

Palavras-chave: Ponta da Praia Norte; Ilha Comprida (SP); Mapeamento Ambiental Participativo (MAP), planejamento e gestão costeira.

\section{Introdução}

As iniciativas de participação social se compõe como ferramenta importante para auxiliar na resolução de problemas de cunho ambiental, uma vez que envolve a interconexão das esferas social, econômica, política e cultural. Quando esta participação abarca a população local de uma determinada área de estudo, que convive cotidianamente com seu lugar e, por sua vez, conhece as problemáticas e as potencialidades postas, temos que a participação se torna ainda mais robusta e coesa para se pensar o lugar, o planejamento, a gestão e o ambiente de maneira integrada, afim de buscar possibilidades de melhorias para a área em questão.

Tendo em vista que as Zonas Costeiras, local onde a Ponta da Praia Norte de Ilha Comprida está inserida, são áreas de estruturas geológico-geomorfológicas naturalmente fragilizadas, e que tal fragilidade por vezes é intensificada pelo processo de uso e ocupação desorganizado e desenfreado que essas áreas vem sofrendo, temos que, tais zonas caracterizam-se em regiões que necessitam de um plano de gestão e planejamento integrado, e que se possível, sejam participativos, para que assim sejam mais fáceis de serem adequados à realidade do local.

De acordo com isso, o presente artigo tem como fundamento metodológico e balizador o Mapeamento Ambiental Participativo (MAP) que pode ser encarado como um importante instrumento de gestão e planejamento ambiental de zonas costeiras, o qual, em nossa pesquisa já teve suas etapas iniciais aplicadas na Ponta da Praia Norte, no munícipio de Ilha Comprida (SP). 
Este trabalho é parte integrante de uma pesquisa de mestrado em geografia que está em andamento, pela Universidade Estadual de Campinas (Unicamp) e sua viabilidade se dá pela real necessidade de interlocução entre os saberes empíricos e científicos como forma de se realizar trocas entre os mesmos.

\section{Potencial do Mapeamento Ambiental Participativo para o planejamento e gestão em áreas costeiras}

O Mapeamento Ambiental Participativo (MAP) é um instrumento de gestão, planejamento e educação ambiental (CARPI JUNIOR \& DAGNINO, 2016) que visa a valorização da percepção da população local, considerando que a experiência cotidiana permite aos moradores melhor resgatar os problemas ambientais e referendar as potencialidades paisagísticas do lugar (SILVA FILHO et. al, 2015). A metodologia do MAP corresponde a três etapas indissociáveis (figura 1) (DAGNINO, 2007), sendo a principal delas a realização de reuniões públicas de mapeamento (execução), momento em que é feito o levantamento de possíveis problemas que afetam o ambiente local e/ou atrativos ambientais como florestas, parques e museus.

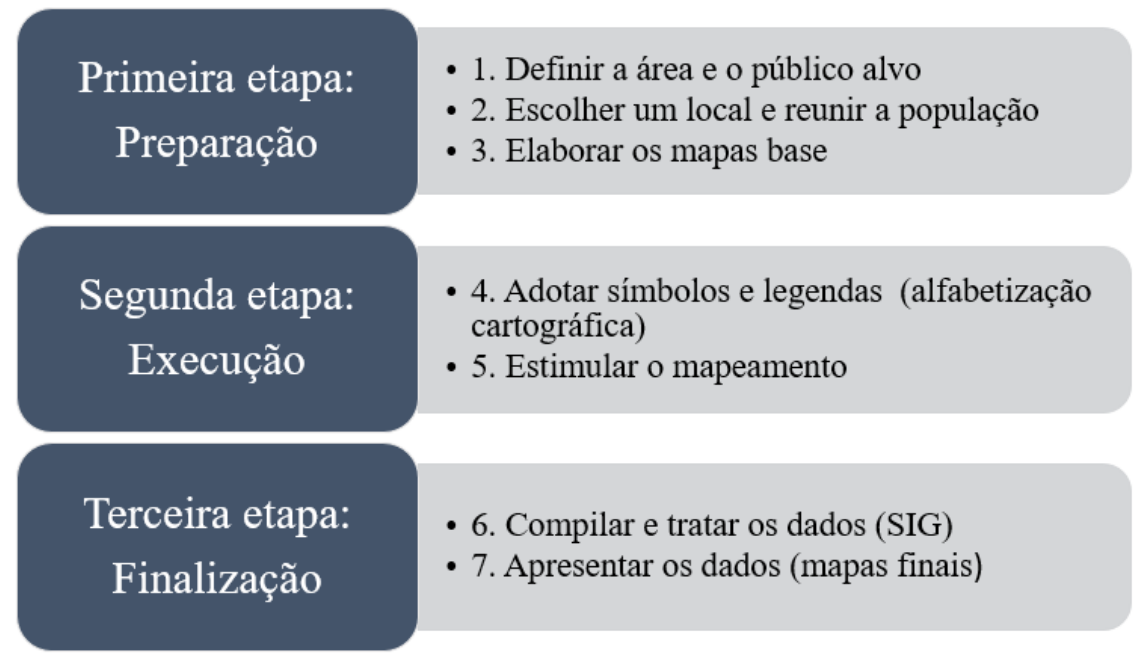

Figura 1 - Etapas do Mapeamento Ambiental Participativo. Fonte: Adaptado de Dagnino (2007).

Durante as reuniões públicas é desejável que haja participação ativa de todos, sem importar o grau de instrução dos sujeitos. Tanto pode ser um doutor, ou até mesmo um trabalhador braçal. O objetivo central é a valorização dos mapas mentais dos participantes, registrados sobre um material cartográfico preparado previamente, a partir de uma legenda-base (figura 2) a partir da qual são desenhadas ou descritas as áreas de riscos ambientais. Esta legenda dispõe de seis eixos principais para caracterização de riscos ambientais, relacionados aos temas água, ar, solo, animais, vegetação, resíduos e 
vulnerabilidade social, que bem pode ser adaptada de acordo com a criatividade e melhor entendimento dos participantes.

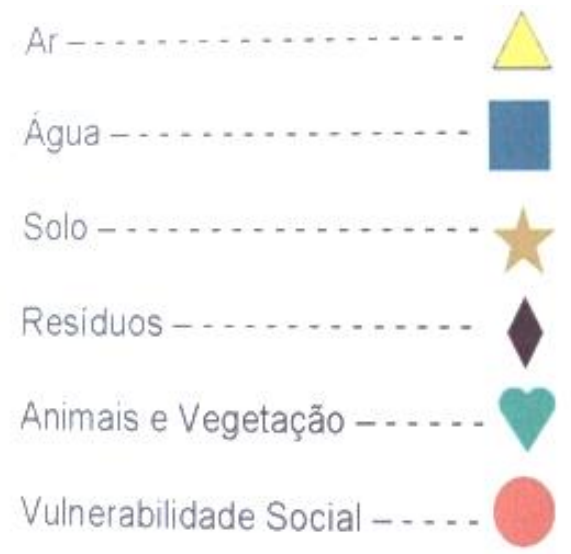

Figura 2 - Exemplo de legenda-base utilizada nas reuniões de mapeamento Fonte: Carpi Jr. et al., 2005.

O Mapeamento Ambiental Participativo (MAP) vem sendo desenvolvido em vários municípios no estado de São Paulo desde a década de 1990, principalmente em estudos de bacias hidrográficas para fins de planejamento de recursos hídricos (quadro 1). 
XVII Simpósio Brasileiro de Geografia Fisica Aplicada

I Congresso Nacional de Geografia Física
OS DESAFIOS DA GEOGRAFIA FÍSICA NA FRONTEIRA DO CONHECIMENTO

Instituto de Geociências - Unicamp

Campinas - SP

28 de Junho à 02 de Julho de 2017

\begin{tabular}{|c|c|c|c|c|c|c|c|c|c|}
\hline 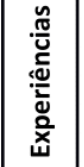 & $\begin{array}{c}\text { Áreas de } \\
\text { Estudo }\end{array}$ & $\begin{array}{l}\text { Área } \\
(\mathrm{km} 2)\end{array}$ & $\begin{array}{c}\begin{array}{c}\text { Período } \\
\text { de } \\
\text { realizaç } \\
\text { ão }\end{array} \\
\end{array}$ & $\begin{array}{l}\text { Pessoas } \\
\text { envolvidas } \\
\text { (aprox.) }\end{array}$ & $\begin{array}{c}\text { Perfil principal } \\
\text { dos } \\
\text { participantes }\end{array}$ & $\begin{array}{l}\text { Demanda ou } \\
\text { iniciativa }\end{array}$ & $\begin{array}{l}\text { Fonte de } \\
\text { recursos }\end{array}$ & $\begin{array}{l}\text { Instituições } \\
\text { envolvidas }\end{array}$ & $\begin{array}{c}\text { Referência } \\
\text { principal do } \\
\text { trabalho } \\
\text { final }\end{array}$ \\
\hline \multirow{5}{*}{ 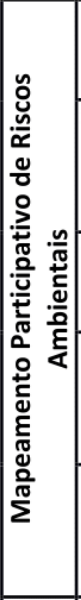 } & $\begin{array}{l}\text { 1. Região de } \\
\text { Campinas }\end{array}$ & 12695 & $\begin{array}{l}1994- \\
1997\end{array}$ & 100 & $\begin{array}{l}\text { Alunos de } \\
\text { curso de } \\
\text { extensão } \\
\end{array}$ & $\begin{array}{l}\text { Coordenador } \\
\text { do Projeto }\end{array}$ & Unicamp & $\begin{array}{c}\text { NEPAM e FEM / } \\
\text { Unicamp }\end{array}$ & $\begin{array}{c}\text { Sevá Filho } \\
\text { (1997) }\end{array}$ \\
\hline & $\begin{array}{l}\text { 2. Bacia do } \\
\text { Rio Mogi- } \\
\text { Guaçu }\end{array}$ & 15397 & $\begin{array}{l}1998- \\
2001\end{array}$ & 330 & $\begin{array}{l}\text { Funcionários } \\
\text { públicos }\end{array}$ & $\begin{array}{l}\text { Comitê da } \\
\text { bacia, } \\
\text { prefeituras } \\
\text { municipais }\end{array}$ & $\begin{array}{l}\text { Prefeituras } \\
\text { Municipais }\end{array}$ & $\begin{array}{c}\text { CBH Mogi, } \\
\text { NEPAM/Unicamp } \\
\text { e CCA/UFSCar }\end{array}$ & $\begin{array}{l}\text { Carpi Jr } \\
(2001)\end{array}$ \\
\hline & $\begin{array}{l}\text { 3. Município } \\
\text { de Apiaí }\end{array}$ & 548 & $\begin{array}{l}2000- \\
2002\end{array}$ & 230 & Estudantes & $\begin{array}{l}\text { Aluna de } \\
\text { mestrado }\end{array}$ & $\begin{array}{l}\text { CNPq e } \\
\text { Unicamp }\end{array}$ & $\begin{array}{c}\text { IG/Unicamp, } \\
\text { Diretoria Estadual } \\
\text { de Ensino }\end{array}$ & $\begin{array}{l}\text { Scaleante } \\
(2002)\end{array}$ \\
\hline & $\begin{array}{l}\text { 4. Bacia do } \\
\text { Ribeirão das } \\
\text { Anhumas }\end{array}$ & 150 & $\begin{array}{l}2004- \\
2006\end{array}$ & 300 & $\begin{array}{c}\text { Comunidade } \\
\text { em geral e } \\
\text { Agentes de } \\
\text { saúde } \\
\end{array}$ & Pesquisadores & FAPESP & $\begin{array}{c}\text { Diversas, } \\
\text { destaque para } \\
\text { IAC, PMC, } \\
\text { IG/Unicamp } \\
\end{array}$ & $\begin{array}{l}\text { Carpi Junior } \\
\text { et al (2006) }\end{array}$ \\
\hline & $\begin{array}{l}\text { 5. Bacia do } \\
\text { Ribeirão das } \\
\text { Pedras }\end{array}$ & 30 & $\begin{array}{l}2005- \\
2007\end{array}$ & 100 & $\begin{array}{l}\text { Comunidade } \\
\text { em geral e } \\
\text { Agentes de } \\
\text { saúde } \\
\end{array}$ & $\begin{array}{l}\text { Aluno de } \\
\text { mestrado }\end{array}$ & $\begin{array}{l}\text { FAPESP e } \\
\text { CAPES }\end{array}$ & $\begin{array}{c}\text { IG/Unicamp, IAC, } \\
\text { PMC }\end{array}$ & $\begin{array}{l}\text { Dagnino } \\
\text { (2007) }\end{array}$ \\
\hline \multirow{11}{*}{ 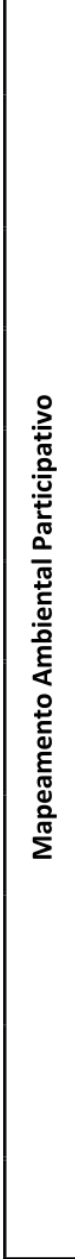 } & $\begin{array}{c}\text { 6. UGRHI } \\
\text { Sorocaba/ } \\
\text { Médio Tietê }\end{array}$ & 9112 & 2010 & 140 & $\begin{array}{l}\text { Membros de } \\
\text { ONG }\end{array}$ & $\begin{array}{l}\text { Coordenadore } \\
\mathrm{s} \text { do projeto }\end{array}$ & FEHIDRO & $\begin{array}{c}\text { OSCIP 5 } \\
\text { Elementos, } \\
\text { IG/Unicamp }\end{array}$ & $\begin{array}{c}\text { Não } \\
\text { publicado }\end{array}$ \\
\hline & $\begin{array}{l}\text { 7. Manancial } \\
\text { Alto Rio } \\
\text { Santo } \\
\text { Anastácio } \\
\end{array}$ & 2154 & $\begin{array}{l}2010- \\
2011\end{array}$ & 210 & $\begin{array}{l}\text { Pequenos } \\
\text { agricultores e } \\
\text { pecuaristas }\end{array}$ & $\begin{array}{l}\text { Pesquisador e } \\
\text { instituição }\end{array}$ & $\begin{array}{l}\text { UNESP- } \\
\text { Presidente } \\
\text { Prudente }\end{array}$ & $\begin{array}{l}\text { UNESP Presidente } \\
\text { Prudente, } \\
\text { IG/Unicamp }\end{array}$ & $\begin{array}{l}\text { Carpi Junior } \\
\text { (2011) }\end{array}$ \\
\hline & $\begin{array}{l}\text { 7.1 Bacia do } \\
\text { Córr. } \\
\text { Palmitalzinho }\end{array}$ & 7,5 & $\begin{array}{l}2010- \\
2011\end{array}$ & 35 & $\begin{array}{c}\text { Pequenos } \\
\text { agricultores e } \\
\text { pecuaristas }\end{array}$ & $\begin{array}{c}\text { Aluno e } \\
\text { instituição }\end{array}$ & \begin{tabular}{|c|} 
UNESP- \\
Presidente \\
Prudente \\
\end{tabular} & \begin{tabular}{|c|} 
UNESP Presidente \\
Prudente, \\
IG/Unicamp \\
\end{tabular} & $\begin{array}{l}\text { Oliveira } \\
\text { (2011) }\end{array}$ \\
\hline & $\begin{array}{l}\text { 7.2 Bacia do } \\
\text { Córr. Embirí }\end{array}$ & 19 & $\begin{array}{l}2010- \\
2011\end{array}$ & 35 & $\begin{array}{c}\text { Pequenos } \\
\text { agricultores e } \\
\text { pecuaristas }\end{array}$ & $\begin{array}{c}\text { Aluno e } \\
\text { instituição }\end{array}$ & \begin{tabular}{|c|} 
UNESP- \\
Presidente \\
Prudente \\
\end{tabular} & \begin{tabular}{|c|} 
UNESP Presidente \\
Prudente, \\
IG/Unicamp \\
\end{tabular} & $\begin{array}{l}\text { Santos } \\
\text { (2011) }\end{array}$ \\
\hline & $\begin{array}{l}\text { 8. Bairro de } \\
\text { Pedrinhas e } \\
\text { entorno (Ilha } \\
\text { Comprida) }\end{array}$ & 4,6 & $\begin{array}{l}2011- \\
2012\end{array}$ & 40 & $\begin{array}{l}\text { População } \\
\text { tradicional e } \\
\text { caiçaras }\end{array}$ & $\begin{array}{l}\text { Aluna de } \\
\text { mestrado }\end{array}$ & FAPESP & IG-Unicamp & $\begin{array}{l}\text { Santos } \\
(2012)\end{array}$ \\
\hline & $\begin{array}{c}\text { 9. UGRHI } \\
\text { Turvo/Grand } \\
\mathrm{e}\end{array}$ & 15955 & $\begin{array}{l}2011- \\
2013 \\
\end{array}$ & 40 & Professores & $\begin{array}{c}\text { Pesquisadores } \\
\text { e técnicos } \\
\text { locais }\end{array}$ & FEHIDRO & $\begin{array}{c}\text { IG/Unicamp e } \\
\text { APTA Centro } \\
\text { Norte } \\
\end{array}$ & $\begin{array}{l}\text { Carpi Junior } \\
\text { et al (2014) }\end{array}$ \\
\hline & $\begin{array}{c}\text { 10. UGRHI } \\
\text { Alto } \\
\text { Paranapane } \\
\text { ma } \\
\end{array}$ & 22581 & $\begin{array}{l}2011- \\
2012\end{array}$ & 80 & $\begin{array}{c}\text { Alunos de } \\
\text { curso de } \\
\text { especialização }\end{array}$ & $\begin{array}{l}\text { Pesquisador e } \\
\text { instituições }\end{array}$ & $\begin{array}{c}\text { FEHIDRO e } \\
\text { FAPESP }\end{array}$ & \begin{tabular}{|c|} 
UNESP Presidente \\
Prudente e \\
Ourinhos, \\
IG/Unicamp \\
\end{tabular} & $\begin{array}{c}\text { Almeida } \\
\text { (2012) }\end{array}$ \\
\hline & $\begin{array}{c}10.1 . \\
\begin{array}{c}\text { Município de } \\
\text { Piraju }\end{array} \\
\end{array}$ & 505 & 2011 & 20 & $\begin{array}{c}\text { Alunos de } \\
\text { curso de } \\
\text { especialização } \\
\end{array}$ & $\begin{array}{l}\text { Pesquisador e } \\
\text { estudante de } \\
\text { especialização }\end{array}$ & FEHIDRO & $\begin{array}{c}\text { UNESP Ourinhos, } \\
\text { IG/Unicamp/NEAD } \\
\text { UNESP } \\
\end{array}$ & $\begin{array}{l}\text { Batista } \\
\text { (2011) }\end{array}$ \\
\hline & $\begin{array}{l}10.2 . \\
\text { Município de } \\
\text { Fartura }\end{array}$ & 429 & $\begin{array}{l}2011- \\
2012\end{array}$ & 10 & $\begin{array}{c}\text { Alunos de } \\
\text { curso de } \\
\text { especialização }\end{array}$ & $\begin{array}{l}\text { Pesquisador e } \\
\text { estudante de } \\
\text { especialização }\end{array}$ & $\begin{array}{c}\text { FEHIDRO e } \\
\text { FAPESP }\end{array}$ & \begin{tabular}{|c|} 
UNESP Presidente \\
Prudente e \\
Ourinhos, \\
IG/Unicamp \\
\end{tabular} & $\begin{array}{l}\text { Almeida } \\
(2012)\end{array}$ \\
\hline & $\begin{array}{l}\text { 10.3. Floresta } \\
\text { Estadual de } \\
\text { Avaré }\end{array}$ & 0,5 & $\begin{array}{l}2012- \\
2013\end{array}$ & 30 & $\begin{array}{c}\text { Funcionários e } \\
\text { frequentadores } \\
\text { da área }\end{array}$ & $\begin{array}{l}\text { Chefe da } \\
\text { Unidade de } \\
\text { Conservação }\end{array}$ & $\begin{array}{c}\text { FEHIDRO e } \\
\text { I.F. }\end{array}$ & IF e IG/UNICAMP & $\begin{array}{l}\text { Carpi Jr, } \\
\text { Silva e } \\
\text { Linder } \\
(2014) \\
\end{array}$ \\
\hline & $\begin{array}{l}\text { 11. Município } \\
\text { de São José } \\
\text { do Rio Pardo }\end{array}$ & 420 & $\begin{array}{l}2014- \\
2016\end{array}$ & 50 & $\begin{array}{l}\text { Pequenos } \\
\text { agricultores e } \\
\text { pecuaristas }\end{array}$ & $\begin{array}{l}\text { Estudante de } \\
\text { mestrado }\end{array}$ & CAPES & $\begin{array}{l}\text { IG/UNICAMP e } \\
\text { Prefeitura } \\
\text { Municipal }\end{array}$ & $\begin{array}{l}\text { SILVA } \\
\text { (2016) }\end{array}$ \\
\hline
\end{tabular}

Quadro 1 - Áreas mapeadas no Estado de São Paulo utilizando o MAP. Fonte: Adaptado de Dagnino e Carpi Jr.

(2016). 
Atualmente o incentivo à participação da sociedade na elaboração de políticas públicas vem ocorrendo desde a criação do Estatuto das Cidades (Lei Federal 10.257/2001), que confere a regulamentação dos artigos 182 e 183 da Constituição Federal de 1988 e viabiliza a criação de Planos Diretores. A utilização de métodos participativos permite que a população atue como indicadora e participante dos problemas existentes de sua comunidade. O governo, na escala municipal, também deve estimular a participação social para criar estratégias com foco em ações socioambientais (SILVA, 2015). Assim, a primazia da troca de saberes técnicos, científicos e populares, fornece subsídios para elaboração de diagnósticos que visam a solução de problemas em áreas de riscos, em especial os ambientais.

É patente que o ambiente costeiro em todo Brasil apresenta uma grande complexidade, pois são áreas ocupadas sem o devido cuidado e planejamento necessário no que se refere às questões de ordem ambiental. Logo, verifica-se a necessidade de estudos e pesquisas que possam contribuir no sentido de poder viabilizar formas e estratégias a fim de auxiliar no planejamento e gestão dessas áreas, como é o caso da Zona de Proteção Especial (ZPE) do município de Ilha Comprida.

Conforme disposto no Plano Nacional de Gerenciamento Costeiro II (1997), a Zona Costeira abriga um mosaico de ecossistemas de alta relevância ambiental, cuja diversidade é marcada pela transição de ambientes terrestres e marinhos, com interações que lhe conferem um caráter de fragilidade e que requerem, por isso, atenção especial do poder público, conforme demonstra sua inserção na Constituição brasileira como área de patrimônio nacional.

Sabendo-se que a fragilidade das zonas costeiras é bastante intensa, como destacam Amorim e Oliveira (2013), as modificações nesses sistemas ambientais pela ação antrópica causam danos irreversíveis, como o desmatamento, aterro de áreas naturais, o lançamento de efluentes domésticos e industriais nos cursos de água alterando construções nas zonas de praias que modificam a paisagem e a dinâmica das correntes costeiras, entre tantos outros problemas de cunho ambiental.

Sendo assim, é de fundamental importância se atentar para um planejamento consistente que tenha um olhar voltado para as problemáticas ambientais, a qual envolve as esferas social, econômica, política e cultural e que, possa ser edificado junto com a população, onde esses atores locais possam apontar problemas e, também, potencialidades locais.

Dessa forma, surge o Mapeamento Ambiental Participativo enquanto metodologia que prima pela participação e valorização da percepção dos indivíduos participantes, pois como bem realça Carpi Junior \& Dagnino (2016), o MAP é semelhante a um ato político em que as pessoas são chamadas a se reunir e são ouvidas, em um processo que valoriza a cultura, a memória coletiva, a percepção, a linguagem popular e a experiência histórica dos participantes.

Depreende-se então que o MAP é um excelente instrumento para a gestão, inclusive de zonas costeiras, tendo em vista que os seus métodos e técnicas corroboram diretamente com a concepção de 
XVII Simpósio Brasileiro de Geografia Fisica Aplicada

I Congresso Nacional de Geografia Física
OS DESAFIOS DA GEOGRAFIA FÍSICA NA FRONTEIRA DO CONHECIMENTO

Instituto de Geociências - Unicamp

Campinas - SP

28 de Junho à 02 de Julho de 2017

participação social e valorização da percepção ambiental dos atores locais para que os mesmos apontem os riscos, vulnerabilidades, assim como, os fatores positivos e potencialidades do lugar, o que evidencia a sua relevância para a edificação de um planejamento consistente e integrado.

\section{3. Área de estudo}

A área de estudo deste trabalho é a Ponta da Praia Norte, que corresponde à Zona de Proteção Especial do município de Ilha Comprida, localizado no litoral extremo Sul do Estado de São Paulo e inserido no contexto da Planície Costeira Cananéia-Iguape (figura 3). Nesta região, a fragilidade ambiental se deve a fatores geológicos (areias quaternárias inconsolidadas finas a muito finas, facilmente erodíveis) e morfológicos (cotas baixas, com altitude média de $\pm 3 \mathrm{~m}$, e exposição a fatores hidrodinâmicos) (BECEGATO, 2007).

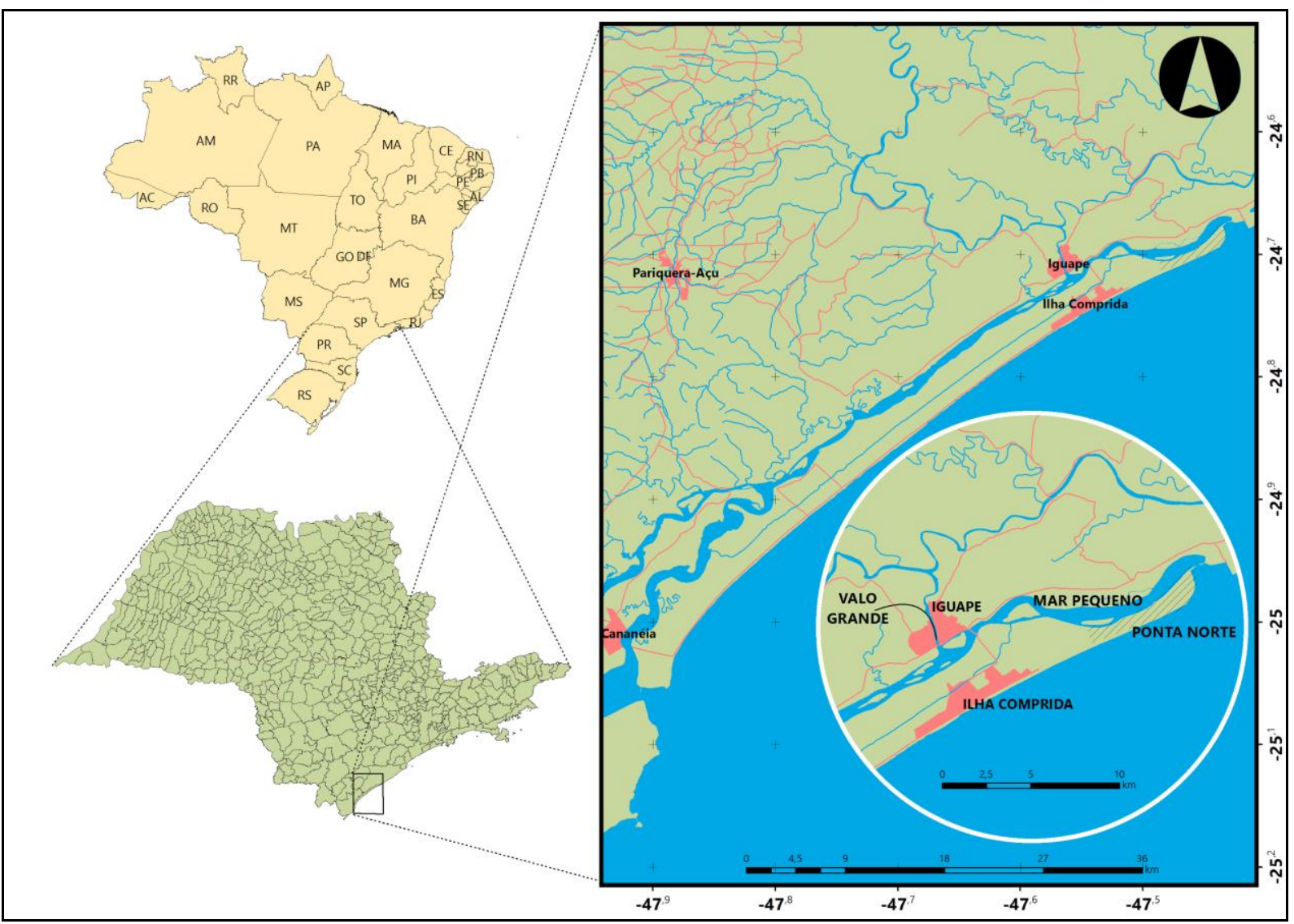

Figura 3. Localização da área de estudo Elaboração: Gustavo Teramatsu (2017)

Apesar das condições naturais adversas, o início da ocupação da Ilha Comprida remonta aos tempos pré-históricos (homens de sambaquis). A intensificação da ocupação humana na região, sobretudo a partir do século XIX, acarretou a construção de obras de engenharia, sendo a mais importante o canal do Valo Grande, concluído em 1855, no município vizinho de Iguape, com a intenção de facilitar o transporte de produtos agrícolas do Vale do Ribeira ao porto de Iguape, desviando o fluxo do Rio 
XVII Simpósio Brasileiro

de Geografia Fisica Aplicada

I Congresso Nacional

de Geografia Física
OS DESAFIOS DA GEOGRAFIA FÍSICA NA FRONTEIRA DO CONHECIMENTO

Instituto de Geociências - Unicamp

Campinas - SP

28 de Junho à 02 de Julho de 2017

Ribeira de Iguape para o complexo lagunar do Mar Pequeno (SANTOS, 2015). A alteração da dinâmica natural provocada pelo Valo Grande acarretou sérios problemas ambientais, como a aceleração do processo de erosão e a sedimentação em extensas porções de terra e cursos d'água (ITALIANI \& MAHIQUES, 2014). A Ponta Norte da Ilha Comprida é uma das regiões mais afetadas por este processo de erosão acelerada, o que vem colocando em risco a população local (figura 4).

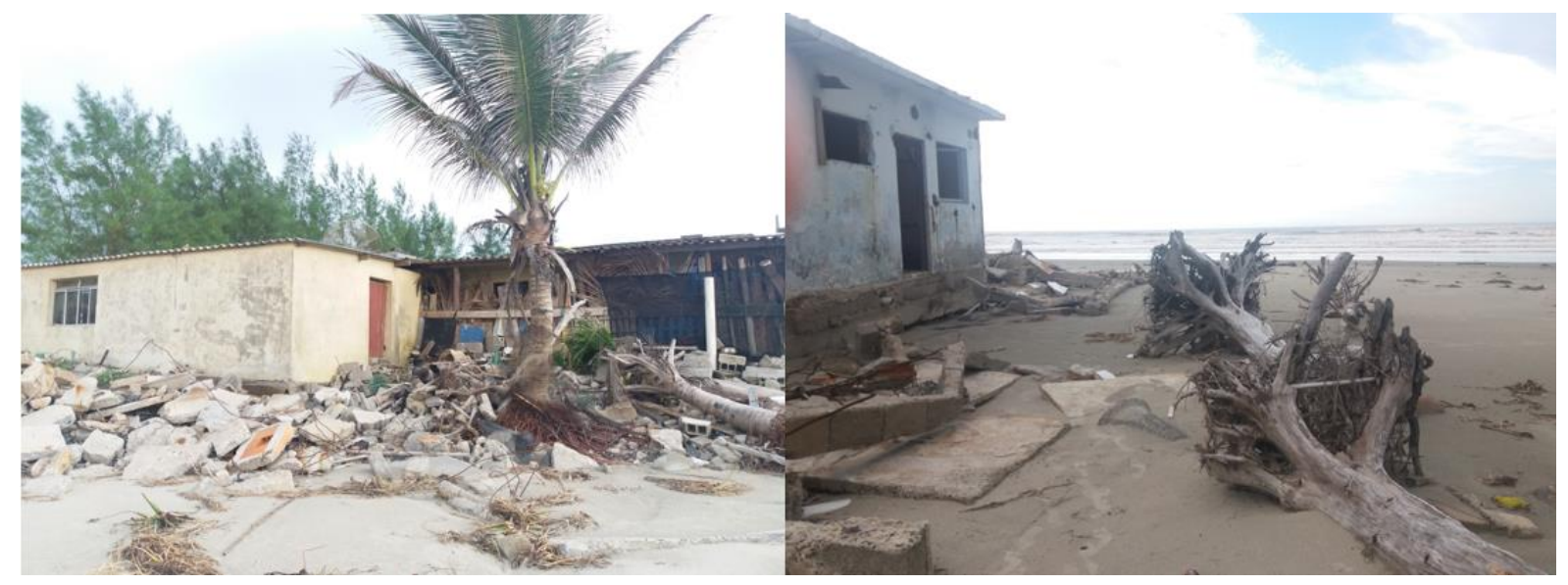

Figura 4 - Edificações destruídas pelo avanço do mar na Ponta da Praia Norte no Município de Ilha Comprida. Fonte: Arquivo dos autores (2017)

\section{Experiências com o Mapeamento Ambiental Participativo no município de Ilha Comprida (SP): breve contextualização e algumas dificuldades encontradas}

Para a aplicação do Mapeamento Ambiental Participativo é necessário seguir uma série de etapas (ver figura 1) para que a reunião pública seja realizada com sucesso e produza bons resultados. Como forma de ajudar nesse processo, o contato inicial e o estabelecimento de parcerias com a população local da área de estudo é de fundamental importância.

Em julho de 2016 foi realizado o primeiro trabalho de campo ao município de Ilha Comprida (SP), estabelecendo-se os contatos iniciais com funcionários da Prefeitura Municipal, da Fundação Florestal de Iguape (gestores da APA Ilha Comprida), da Fundação Florestal de Cananeia (gestores da APA Marinha do Litoral Sul), moradores do Boqueirão Norte e moradores da Vila Caiçara de Pedrinhas. Com essas pessoas tivemos breves conversas onde explicamos o intuito de nossa pesquisa, além de verificar a possibilidade e a viabilidade de trabalhar a metodologia do MAP com a população local da Ilha Comprida.

Uma das informações que conseguimos extrair deste primeiro contato com parte da população, foi que pelo fato de a Ilha Comprida e sua região já ter tido inúmeros trabalhos de cunho participativo, promovidos por órgãos federais, estaduais e municipais, e inclusive por vários pesquisadores, parte da população local acabou perdendo o interesse em participar de reuniões públicas participativas de novos trabalhos. Segundo os entrevistados, o grande motivo disto é que na maioria das vezes, havia 
participação popular, mas ao final de algumas pesquisas, não existiram retornos com os principais resultados obtidos sobre tais participações, ou por muitas vezes, os trabalhos eram inacabados.

Várias reuniões participativas já foram realizadas com a população da Ilha Comprida visando a elaboração de documentos importantes para o planejamento e gestão da cidade, como por exemplo, elaboração do Plano de Manejo e do Plano Diretor. Porém, desde 1987, ano de criação da APA Ilha Comprida, até o presente momento a Ilha Comprida ainda não dispõe de um Plano de Manejo concluído. O mesmo ocorre com o Plano Diretor. Desde 1991, ano em que a ilha se emancipou a categoria de município, a cidade ainda não possui, também, este documento, o qual, segundo o Estatuto das Cidades, é obrigatório para áreas de interesse turístico e áreas que possuam forte influência de empreendimentos ou atividades com significativo impacto ambiental, como é o caso da Ilha Comprida.

Outra experiência que a população local da Ilha Comprida e região teve com reuniões participativas ocorreu no final de 1996. Neste ano, em busca da sustentabilidade do Vale do Ribeira e Litoral Sul, foram feitas Oficinas de Treinamento para a Elaboração de Diagnóstico Participativo (DP) do Vale do Ribeira, realizadas nos municípios de Peruíbe, Iguape, Miracatu, Ilha Comprida, Pedro de Toledo, Cananeia, Juquiá e Itariri. Estas reuniões foram produto do projeto de parceria entre o Instituto Brasileiro do Meio Ambiente e dos Recursos Naturais Renováveis (IBAMA), a Secretaria de Estado do Meio Ambiente (SMA) e a Universidade Estadual de Campinas (Unicamp), o qual possuía documento que materializava dois objetivos principais: a democratização da gestão dos recursos naturais e a popularização da metodologia científica que resultaria na participação da sociedade no levantamento de informações sobre uma dada realidade que se pretende transformar através de políticas e programas de governo (IBAMA - SMA- UNICAMP, 1998).

Também foram realizadas na Ilha Comprida no ano de 2012, reuniões participativas organizadas pela Petrobrás com fins de obter Diagnóstico Participativo (DP) do Programa de Educação Ambiental, desenvolvido na área de influência dos empreendimentos de exploração, produção e escoamento de petróleo e gás na região 3 - São Paulo (PEA-SP) da Bacia de Santos, cujo processo de licenciamento é conduzido pela CGPEG/IBAMA (PETRÓLEO BRASILEIRO S. A., 2012).

Em setembro de 2016, durante o segundo trabalho de campo, desta vez em Cananeia, município vizinho de Ilha Comprida, foi vivenciada a retomada das reuniões participativas do Plano de Manejo da APA Marinha do Litoral Sul, das quais, duas foram realizadas na Ilha Comprida (Pedrinhas e Boqueirão Sul). Basicamente trataram-se de reuniões do Conselho Gestor Ampliado, uma vez que este estava convidando outros atores além dos conselheiros. O objetivo principal do encontro foi explicar como se daria a retomada do Plano de Manejo da Unidade (APAMLS), apresentar os principais resultados do Diagnóstico Participativo, elaborado a partir das oficinas participativas realizadas com 
os usuários da APAMLS no ano de 2013, e apresentar as próximas etapas previstas do Plano de Manejo, esclarecendo dúvidas sobre o processo.

Diante do acompanhamento destas atividades, ocorreu uma ampliação de conhecimento a respeito de métodos participativos e sobre diferentes formas de aplicação, bem como foram obtidas indicações de contatos de pessoas chaves para nos auxiliar na aplicação do MAP na Ponta da Praia Norte em Ilha Comprida.

Como forma de dar continuidade a organização da primeira etapa de aplicação do MAP (preparação) na Ponta da Praia Norte em Ilha Comprida, em janeiro de 2017, realizamos terceiro trabalho de campo para a área de estudo. Nesta visita, foi possível acompanhar reuniões e conversas com funcionários do Departamento de Desenvolvimento Local da Prefeitura Municipal de Ilha Comprida, assim como com gestores da APA Ilha Comprida, uma agente de saúde do Posto de Saúde do Araçá (posto de saúde mais próximo da Ponta da Praia Norte e que faz a contabilização das famílias residentes nesta área), além de alguns moradores da região de estudo.

Este último trabalho foi de extrema importância para a pesquisa, pois foi nele que parcerias fundamentais com pessoas chaves do município foram formalizadas, as quais contribuíram com diversas informações norteadoras para a continuidade das próximas etapas do MAP. De todos os entrevistados, foram coletadas informações como e-mail e telefones para estabelecer contato posterior e convidá-los para participar da primeira reunião pública, que está prevista para acontecer em abril de 2017.

Foi durante também este último trabalho de campo que foram apresentados alguns lugares propícios para a realização da primeira reunião, sendo um deles um salão localizado na Ponta da Praia Norte, o qual é de fácil acesso para a população residente de suas proximidades.

Importante destacar que, de acordo com o quadro 1, no ano de 2012, o município de Ilha Comprida já contou com uma experiência utilizando o MAP como uma de suas metodologias de pesquisa. $\mathrm{O}$ trabalho foi desenvolvido por Santos (2012), onde o intuito foi resgatar parte do conhecimento da população local da Vila de Pedrinhas, maior vila e comunidade tradicional de caiçaras de Ilha Comprida, através da aplicação do MAP, como forma de cartografar informações importantes advindas da população sobre seu lugar de morada, e por fim utilizá-las como instrumentos de planejamento e gestão do local (SANTOS, 2012).

E por fim, encontra-se em andamento em 2017, segunda pesquisa acadêmica que utiliza o MAP como uma de suas metodologias aplicada em áreas litorâneas. Nesta pesquisa, a área litorânea abordada ainda faz parte do Litoral Sul, na Ilha Comprida, só que agora com foco para a região e população da Ponta da Praia Norte. 


\section{Considerações Finais}

Sabe-se que as Zonas Costeiras apresentam estruturas geológicas e geomorfológicas extremamente frágeis. Sendo assim, as alterações naturais dessas zonas, somadas a alguns fatores antrópicos, acarretam uma série de problemas ambientais, como por exemplo a erosão acelerada que está ocorrendo na Ponta da Praia Norte na Ilha Comprida, o que acaba colocando em risco construções, o meio ambiente e a população local.

Neste trabalho, foi realçada a importância do Mapeamento Ambiental Participativo e sua contribuição ao planejamento da Zona Costeira na Ponta da Praia Norte no município de Ilha Comprida. O MAP funciona como uma metodologia capaz de conseguir integrar várias facetas inerentes ao processo participativo, tendo a população participante como indicadora tanto das problemáticas, quanto das potencialidades do lugar em estudo contribuindo também, para a edificação de um planejamento democrático e integrado.

Vale salientar que, até o momento conseguimos aplicar a primeira etapa (preparação) quase que completa do MAP na Ponta da Praia Norte no município de Ilha Comprida, na qual foi estabelecido um contato primeiro com alguns órgãos e pessoas chaves do município em questão, para assim poder enfatizar a importância da realização e objetivos de aplicação desta metodologia participativa.

No primeiro trabalho de campo realizado, com base em alguns relatos dos entrevistados, percebeu-se uma certa dificuldade para a aplicação do MAP, uma vez que os mesmos destacaram que havia um certo desinteresse por parte da população local em participar de reuniões públicas de caráter participativo. O que acontecia era que vários órgãos que já tinham iniciado trabalhos bem semelhantes aos do MAP, por vezes não os concluíam, e quando o contrário ocorria, não davam o devido retorno para a população interessada e que participou das atividades por eles propostas.

A não finalização de documentos relevantes para a o desenvolvimento sustentável, planejamento e gestão da cidade, como o Plano de Manejo e Plano Diretor, é fator agravante para a insatisfação popular para com práticas participativas na Ilha Comprida e região.

Mesmo assim, de frente com toda essa problemática, foi dada continuidade ao trabalho na área de estudo, através da realização de mais dois trabalhos de campo, que trouxeram resultados significativos e importantes para a execução da primeira etapa (preparação) do MAP.

Estes três trabalhos de campo realizados na área de estudo até o presente momento tiveram grande relevância para a pesquisa, tendo em vista a construção de parcerias, as quais são fundamentais para a realização da primeira reunião pública de caráter participativo, a qual se constitui na principal etapa do MAP. 
Por fim, esperamos que esta pesquisa seja valorizada não apenas por todos aqueles que de uma forma ou de outra estão diretamente envolvidos com a mesma, mas também, e principalmente, pelos órgãos públicos e privados que detém poder para tentar melhorar as condições ambientais e também a vida das populações residentes em áreas de risco ambiental através de investimentos em políticas públicas efetivas.

\section{Agradecimentos}

Agradecemos ao apoio financeiro dado pela CAPES. À todos os moradores e moradoras da Ilha Comprida, funcionários e funcionárias da Fundação Florestal de Iguape e de Cananeia, assim como da Prefeitura Municipal de Ilha Comprida, os quais nos cederam entrevistas e apoio para o desenvolver desta pesquisa. Ao Gustavo Teramatsu, pela revisão ortográfica deste artigo e elaboração do mapa de localização da área de estudo. E à Prof ${ }^{a}$. Regina Célia de Oliveira e ao Prof. Salvador Carpi Jr, pelas orientações e contribuições a esta pesquisa.

\section{BIBLIOGRAFIA}

AMORIM, Raul Reis; OLIVEIRA, Regina Célia. Zoneamento ambiental, subsídio ao planejamento no uso e ocupação das terras da costa do descobrimento. Mercator, Fortaleza, v. 12, n. 29, set./dez. 2013, p. 211-231.

BECEGATO, J. L. Impacto ambiental antrópico na APA (Área de Proteção Ambiental) da Ilha Comprida (SP), da Pré-História à atualidade. Universidade de Guarulhos. Dissertação de mestrado (Análise Geoambiental). Guarulhos, 2007.

BRASIL. Constituição (1988). Constituição da República Federativa do Brasil: promulgada em 5 de outubro de 1988.

CARPI JUNIOR., S., et. al. Riscos ambientais na Bacia do Rio Mogi-Guaçu: proposta metodológica. Geografia, Rio Claro, v. 30, n. 2, p. 347-364, 2005.

CIRM. II Plano Nacional de Gerenciamento Costeiro (PNGC II). Brasília. 1997.

DAGNINO, R. de S. Riscos ambientais na bacia hidrográfica do Ribeirão das Pedras, Campinas/São Paulo. 2007. 127 p. Dissertação (Mestrado), Geografia, Universidade Estadual de Campinas, Instituto de Geociências, Campinas, 2007.

DAGNINO, R. de S; CARPI JUNIOR. História, Desafios e Perspectivas do Mapeamento Ambiental Participativo no Estado de São Paulo, In: DIAS, L.S.: BENINI, S. Estudos Ambientais Aplicados em Bacias Hidrográficas. 2 ed. Tupã, ANAP, pp. 13-28, 2016.

IBAMA - SMA - UNICAMP: Instituto Brasileiro de Meio Ambiente e dos Recursos Naturais Renováveis; Secretaria de Estado de Meio Ambiente; Universidade Estadual de Campinas. Diagnóstico ambiental participativo do Vale do Ribeira e Litoral Sul de São Paulo. São Paulo: Secretaria de Estado de Meio Ambiente, v.1, 1998. 85 p.

ITALIANI, D. M; MAHIQUES, M. M. O registro geológico da atividade antropogênica na região do Valo Grande, Estado de São Paulo, Brasil. Quaternary and Environmental Geosciences 2014, 5, 2, pp. 33-44. Disponível em< http://revistas.ufpr.br/abequa/article/view/34522/23346>. Acesso em: fevereiro de 2017.

PETRÓLEO BRASILEIRO S.A. (PETROBRÁS). Diagnóstico Participativo Programa de Educação Ambiental PEA-SP - Região 03. Relatório final de Diagnóstico Participativo do Litoral Sul, nov. 2012.

SANTOS, F. M. Dinâmica populacional e mudanças ambientais: riscos e adaptação em Ilha Comprida, Litoral Sul de São Paulo. 2015. 210 p. Tese (doutorado) - Universidade Estadual de Campinas, Instituto de Filosofia e Ciências Humanas, Campinas, SP, 2015. 
SANTOS, V. C. Alterações ambientais no município de Ilha Comprida, SP: estudo de caso da comunidade caiçara do bairro de Pedrinhas. 2012. 175 f. Dissertação (Mestrado em Geografia) - Instituto de Geociências, Universidade Estadual de Campinas, Campinas, 2012.

SILVA, Amanda Cristina Alves. Mapeamento participativo de riscos ambientais no bairro rural Água Fria, São José do Rio Pardo. 2015. 67 p. Monografia (Bacharelado), Geografia, Universidade Estadual de Campinas, Instituto de Geociências, Campinas, 2015.

SILVA FILHO, Jeovanes Lisboa; SILVA, Amanda Cristina Alves; CARPI JUNIOR, Salvador. Mapeamento Participativo Aplicado ao Estudo de Riscos Ambientais no Bairro rural Sítio Novo, São José do Rio Pardo, São Paulo. In: Periódico Eletrônico do XI Fórum Ambiental da Alta Paulista. Educação Ambiental. v 11, n 04, 2015, pp. 55-67. 